\title{
SARS Cov2 experience in the south of Italy
}

Fiori Patrizia $^{1 *}$, Cataldo Donato ${ }^{2}$, Cavalli Antonella ${ }^{2}$, Ciano Giovanni' ${ }^{2}$, Cocca Carmen ${ }^{2}$, D’Amato Remigio $^{2}$, Di Cicilia Stefania ${ }^{2}$, Lo Calzo Fabio $^{2}$, Luca Franco ${ }^{2}$, Nevola Riccardo ${ }^{2}$, Panico Antonio ${ }^{2}$, Pelosi Chiara ${ }^{2}$, Rinaldi Giovanni ${ }^{2}$, Savino Patrizia ${ }^{2}$, Capaldo Guglielmo ${ }^{1}$, Corbo Antonio $^{1}$, Iorillo Luigi ${ }^{1}$, Massarelli Marco ${ }^{1}$, Bianchino Giuseppe ${ }^{3}$, Di Gianni Angela ${ }^{3}$, Gualdiero Pasquale ${ }^{3}$, Lo Conte Carmela ${ }^{3}$, Manganelli Gianvito $^{3}$, Minichiello Stefania ${ }^{3}$, Pellecchia Vincenzo ${ }^{3}$, Romano Giuseppina ${ }^{4}$, Benigni Giovanni ${ }^{6}$, Damiano Terenzio ${ }^{6}$, Pace Erminio ${ }^{6}$, Brogna Barbara $^{7}$, Martino Alberigo ${ }^{7}$, Belmonte Gerardo ${ }^{9}$, Grappone Mario ${ }^{9}$, Gizzi Raffaele ${ }^{10}$, Bellizzi Gennaro ${ }^{3}$, Caraglia Michele ${ }^{11}$, Ferrara Maurizio $^{6}$, Frieri Angelo ${ }^{9}$, Mazza Emerico ${ }^{7}$, Monaco Antonio ${ }^{1}$, Tammaro C.A. ${ }^{9}$, Bellizzi Annamaria ${ }^{2}$, Grasso Gerardo ${ }^{5}$, Musto Daniela ${ }^{5}$ and D'Agostino Silvio ${ }^{8}$

${ }^{1}$ Neurological Unit, S. Ottone Frangipane Hospital, ASL AV, 83031 Ariano irpino, University of Naples, Italy ${ }^{2}$ Internal Medicine, S. Ottone Frangipane Hospital, ASL AV, 83031 Ariano irpino, University of Naples, Italy ${ }^{3}$ Cardiology, S. Ottone Frangipane Hospital, ASL AV, 83031 Ariano irpino, University of Naples, Italy

${ }^{4}$ Nephrology, S. Ottone Frangipane Hospital, ASL AV, 83031 Ariano irpino, University of Naples, Italy

${ }^{5}$ Surgery, S. Ottone Frangipane Hospital, ASL AV, 83031 Ariano irpino, University of Naples, Italy

${ }^{6}$ Intensive Care, S. Ottone Frangipane Hospital, ASL AV, 83031 Ariano irpino, University of Naples, Italy

${ }^{7}$ Radiology, S. Ottone Frangipane Hospital, ASL AV, 83031 Ariano irpino, University of Naples, Italy

${ }^{8}$ First Aid, S. Ottone Frangipane Hospital, ASL AV, 83031 Ariano irpino, University of Naples, Italy

${ }^{9}$ Laboratory, S. Ottone Frangipane Hospital, ASL AV, 83031 Ariano irpino, Criscuoli Hospital, 83054 S. Angelo dei Lombardi, ASL AV, University of Naples, Italy

${ }^{10}$ Rehabilitation, Criscuoli Hospital, 83054 S. Angelo dei Lombardi, ASL AV, University of Naples, Italy

${ }^{11}$ Department of Experimental Medicine, BIOGEM Institute of Genetic Research, Laboratory of Molecular and Precision Oncology, 83031 Ariano irpino, University of Naples, Italy

\begin{abstract}
Coronavirus $2(\mathrm{CoV} 2)$ is challenging health care and economical asset all over the world. We report our experience in the CoV2 unit in a southern, Italian community hospital. Eighty-nine patients came to our observation for suspected CoV2 infection. After clinical evaluation, oro-pharyngeal and/or nasal swabs, blood withdrawals and radiological examinations were performed. At admission, Brescia Covid Scale was higher in non-survivors compared to survivors, especially in lymphopenic patients. Higher levels of C Reactive Protein (CRP) and Procalcitonin (PCT) were present in lymphopenic, non-survivors compared to survivors. Creatinine (Cre) was higher both in lymphopenic and no lymphopenic non-survivors compared to survivors. At the last control, a decrease in CRP in all survivors, an increase of PCT in all non-survivors were revealed. A lower absolute lymphocyte count and higher d-dimer and creatinine were present in lymphopenic, non-survivors. CRP and creatinine increased, while absolute lymphocyte count decreased in no lymphopenic, non-survivors. The majority of our patients had interstitial pneumonia with typical ground-glass lesions. Comorbidities weighted on disease evolution. Overall the mortality was low compared to the northern of Italy, because of early diagnosis and therapy, screening on all the inhabitants, low level of environmental pollution. Our data highlight the pivotal role of classifying severity of clinical conditions according to the comorbidities and the immunological asset. We propose a scale for promptly defining clinical setting, treatments and prognosis.
\end{abstract}

\section{Introduction}

Coronaviruses $(\mathrm{CoV})$ were described as mite agents, causing benign, self-limiting upper respiratory tract and intestinal infections. Asian outbreaks of CoV- related Severe Acute Respiratory Syndrome (SARS) and Middle East Respiratory Syndrome (MERS) pointed out the risk of contagion diffusion, related morbidity and mortality (the latter being around $10 \%$ and $35 \%$, respectively) [1-5]. Pandemia of CoV2 SARS threatened health care and economical steady state all over the world. This virus is homologous with human SARS and MERS viruses [6]. It is a small, round-oval, single, positive-strand RNA b-CoV (Sarbecovirus subgenus, Orthocoronavirinae subfamily, Nidovirales order), of $60-140 \mathrm{~nm}$ in diameter. It is constituted by six essential structural proteins, namely spike (S) glycoprotein, small envelope (E) protein, matrix $(\mathrm{M})$ protein, nucleocapsid $(\mathrm{N})$ protein, a replicase transcriptase complex (RTC), with two overlapping open reading frames (ORFa and $\mathrm{ORFb}$ ).
The name of $\mathrm{CoV}$ was conferred because of peculiar crown aspect of club-shape S projections on the membrane. S1 protein anchors on host Angiotensin Converting Enzyme 2 Receptor (Ace2R) and S2 protein mediates viral-cell membrane fusion by two tandem domains, heptad repeats 1 and 2. Transmembrane Serine Protease 2, phosphoinositide 5 kinase, 2-pore-segment channel 2 and cathepsin $\mathrm{L}$ play a critical role in viral penetration into the cells. By viral RNA translation into the cytoplasm, the RTC is activated, transcription is

${ }^{\star}$ Correspondence to: Fiori Patrizia, Neurological Unit, S. Ottone Frangipane Hospital, Ariano irpino (AV), ASL AV, University of Naples, Italy, Tel: 39-825877602; Fax 39-825-828409; E-mail patriziafiorirmit@alice.it

Key words: CoV2 infection, comorbidities, immunological asset

Received: September 16, 2020; Accepted: September 25, 2020; Published: September 30, 2020 
started up, viral synthesis, replication and release rapidly occur [7-13]. $\mathrm{M}$ protein is a structural protein, determining viral shape. Interactions of N protein tethers viral RNA to RTC and packages the encapsidated genome into viral particles. $\mathrm{E}$ is a transmembrane protein with ion channel activity, facilitating viral assembly and release. Exceeding $S$ proteins, not assembled into virion, transit to the cell surface and mediate cell-cell fusion between infected cells and adjacent, uninfected cells, leading to the formation of syncytial, giant, multinucleated cells. This may contribute to immune escape and favor viral spreading. Ace $2 \mathrm{R}$ downregulation and subsequent reduction of angiotensin II inactivation and conversion to angiotensin 1-7 trigger a cascade of phenomena, leading to inflammation, humoral and cellular immune reactions, cytokine storm, hyper-viscosity and coagulability, endothelial and parenchymal damage. Wild inferior vertebrates are viral reservoirs, superior vertebrates may be amplifying hosts. Human transmission may occur through respiratory droplets, aerosol, fecal-oral route, direct contact, blood, mother-to-child included [14-17]. The latency period is generally from 3 to 7 days, with a maximum of 14 days [18], although up to 32 days are reported [19]. Many questions have still not found answers. Why coronavirus was so virulent also in developed countries? Are asymptomatic carriers a source of contagion? How long does immunocompetence last? Will viral mutagenesis rate allow prompt development of effective vaccines?

We report our experience in the CoV2 unit in an Italian, southern community hospital.

\section{Materials and methods}

Since February to May 2020, 89 patients (age 72,89 sd 16,08 years old) (46 males, age 71,37 sd 14,33; 43 females, age 74,05 sd 17,79) came to our observation for suspected CoV2 SARS infection. Brescia Covid Score was calculated [20]. All patients underwent blood withdrawals and oro-pharyngeal and/or nasal swab. The specimens were immediately transferred to laboratory. Differential diagnosis with Streptococcus Pneumoniae, Pneumococcus Pneumoniae, Mycoplama pneumoniae, Legionella pneumophila and Mycobacterium Tubercolosis was considered.

Multiplex Real-time reverse transcriptase-polymerase chain reaction (TaqPath COVID19 CE-IVD RT-PCR kit, ThermoFisher Scientific, Applied Biosystems 7500 Fast Real-Time PCR Instrument, COVID19 Interpretive Software, Life Technologies Corporation, Pleasanton, CA, USA) was performed for qualitative detection of CoV2 nucleic acid. After cellular lysis with Trizol reagent, silica-cartridge RNA purification and elution by RNase-Free water, RNA nucleic acids were transferred to MicroAmpTM Optical Well Reaction plate for conversion to cDNA by reverse transcriptase activity of DNA polymerase and cycles of amplification, followed by binding to target specific fluorescent labeled oligonucleotide probes for detection of ORF1ab, N Protein, $S$ protein genes.

Rapid test for qualitative detection of IgM and IgG against CoV2 (KHB, Shanghai Kehua Bio-engineering Co, Ltd) was performed in 44/89 patients by lateral flow immunoassay chromatography with CoV2 antigen/chicken-IgY conjugated with colloidal gold.

Blood Cell Counts was examined by XN 2000 Hematology Analyzer (Sysmex Corporation).

C Reactive Protein (CRP) was detected by latex immunoturbimetric assay (Multigent CRP, Vario assay, Sentinel CH SpA, Milan, Italy) using the Architect cSystems. Anti-CRP antibody absorbed to latex particles reacted with CRP present in the serum. The agglutination was detected as absorbance change. Normal range value was $0-5 \mathrm{mg} / \mathrm{L}$.

Procalcitonin (PCT) was assessed by chemiluminescence, sandwich immunoassay with paramagnetic microparticles and mouse monoclonal anti-katacalcin antibodies in solid phase, labeled with isoluminol, mouse monoclonal anti-calcitonin antibodies (Liaison Brahms PCT II GEN, Diasorin, Saluggia (VI), Italy). Normal range value was $0,02-0,5 \mathrm{ng} / \mathrm{ml}$.

D-dimer (d-dim, Innovance, Dade Behring, Deerfield, Illinois, USA, Siemens Healthcare Diagnostics, Milan, Italy) was determined by immunoturbidimetric application with polystyrene particles, coated with monoclonal mouse antibodies against d-dim, on Sysmex analyzer. Normal range value was $0-0,5 \mathrm{mg} / \mathrm{L}$.

Creatinine (Cre) (Abbott, Wiesbaden, Germany) was evaluated by reaction with sodium picrate and measurement of absorbance through Architect cSystem. Normal range value was $0,7-1,2 \mathrm{mg} / \mathrm{dl}$ for men and 0,5-0,9 mg/dl for women.

High-sensitive Troponin (hsTro) (Beckman Coulter Access hsTnI, Brea, CA, USA) was detected by sandwich, electrochemiluminescence immunoassay. Alkalin phosphatase conjugated, sheep monoclonal antibodies anti-human-hsTro were incubated with the samples and mouse monoclonal anti-human-hsTro coated with paramagnetic microparticles. After removal of unbound materials and addiction of chemiluminescent substrate, light was measured with a luminometer Access 2 Immunoassay System. Normal value was $<11,6 \mathrm{ng} / \mathrm{L}$.

Haemogasanalysis was revealed by GEM Premier 5000 whole blood testing system (Critical Care Instrumentation Laboratory, Bedford, MA,USA). Normal range values were: $\mathrm{pH} 7,35-7,45, \mathrm{pO}_{2} 80$ $110 \mathrm{mmol} / \mathrm{L}, \mathrm{pCO}_{2} 35-45 \mathrm{mmHg}, \mathrm{HCO}_{3} 22-28 \mathrm{mmol} / \mathrm{L}, \mathrm{HCO}_{3} \mathrm{STD}$ 22-28 mmol/L, $\mathrm{SaO}_{2}$ 95-98\%. Hypoxemia was defined by standard criteria $\left(\mathrm{SaO}_{2}<90 \%, \mathrm{PaO}_{2}<60 \mathrm{mmHg}, \mathrm{FiO}_{2} \mathrm{PaO}_{2} / \mathrm{FiO}_{2}<300 \mathrm{mmHg}\right)$. We referred to Berlin's classification of its severity (- mild $\mathrm{mmHg} \mathrm{PaO}_{2} /$ $\mathrm{FiO}_{2}<300 \mathrm{mmHg}$; - moderate $<200 \mathrm{PaO}_{2} / \mathrm{FiO}_{2}<300 \mathrm{mmHg}$; severe $<100 \mathrm{PaO}_{2} / \mathrm{FiO}_{2}$ [21].

Chest X-Ray and Computerized Tomography (High Resolution Chest CT GE OPTIMA 64 Slice Tomograph) were performed within 24 hours after admission and repeated, according to clinical conditions.

Data were statistically analyzed by unpaired T-Test for standard description of baseline characteristics and differences among the studied groups, by Pearson correlation test and regression analysis, for identification of association among examined parameters.

\section{Results}

At admission, Brescia Cov2 Scale was 0,71 sd 1,34. The most common clinical manifestation was fever $(52 / 89,58,4 \%)$, followed by dyspnea $(40 / 89,44,9 \%)$, fatigue $(32 / 89,36 \%)$, cough $(29 / 89,32,6 \%)$, gastro-intestinal signs $(21 / 89,23,6 \%)$, arthralgias $(15 / 89,16,9 \%)$, myalgias $(15 / 89,16,9 \%)$, congested or runny nose/sore throat $(8 / 89$, 9\%) (Figure 1).

The majority of elderly patients $(62 / 89,70 \%)$ presented neurological signs, represented by speech disturbs (dysphasia $37 / 89,42 \%$; dysarthria $51 / 89,57 \%)$, confusion $(50 / 89,56 \%)$, agitation (14/89, 16\%). Headache, anxiety, dizziness, anosmia and ageusia were reported by $23 / 89(26 \%)$, 12/89 (13\%), 9/89 (10\%), 5/89 (6\%) patients, respectively (Figure 2). 


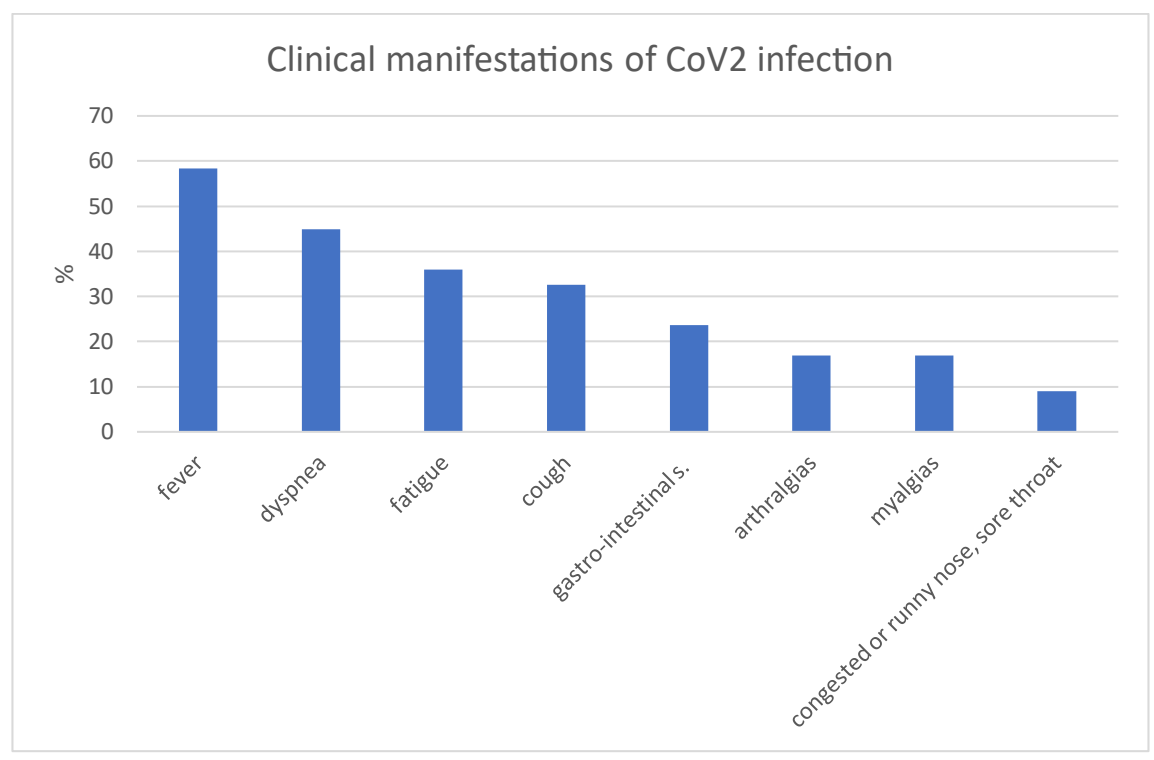

Figure 1. Percentage of patients with clinical manifestations in CoV2 infection

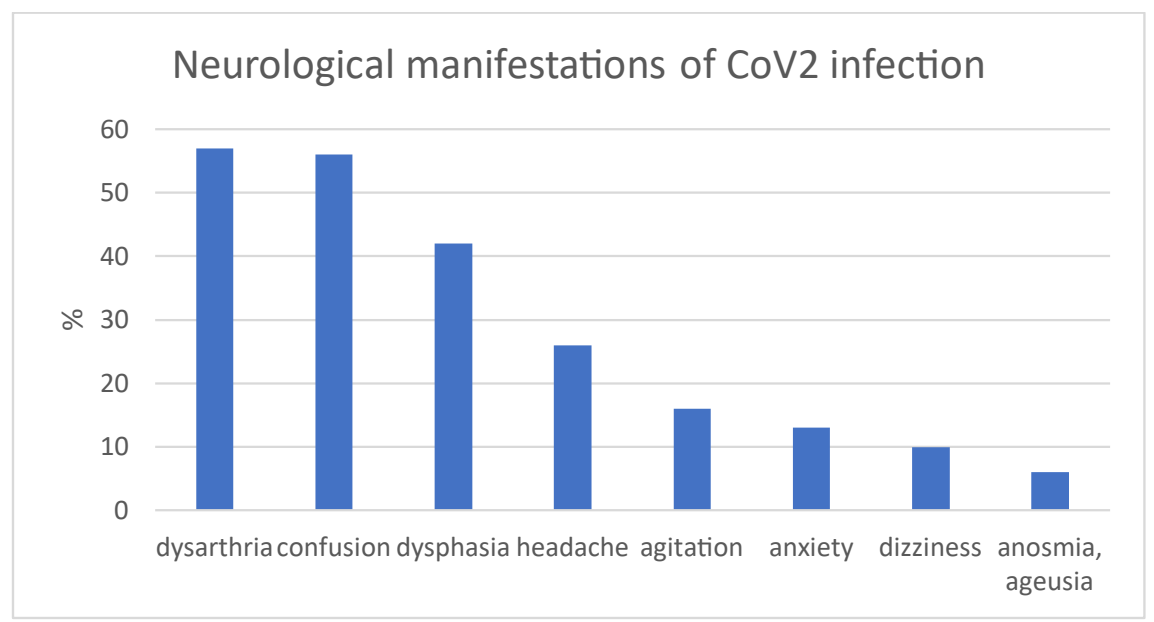

Figure 2. Percentage of patients with neurological manifestations in CoV2 infections

Hypoxic encephalopathy was present in 36/89 (40\%) patients. $\mathrm{CoV} 2$ infection was observed in the context of a typical haemorrhagic acute stroke in one patient suffering from arterial hypertension. Two patients had ischaemic stroke during the course of CoV2 SARS. The etiopathogenesis was lacunar in the young, male patient, affected with arterial hypertension, and embolic in the elderly, female patient, suffering from permanent atrial fibrillation.

Preliminary examinations of radiological images of full-blown disease showed interstitial pneumonia in $90 \%$. The dominant distribution was along broncho-vascular axis (74\%), while subpleural involvement was present in (68\%). Mostly, multiple lesions were observed (85\%). Their shape was heterogeneous, as well as the density: ground-glass shadow (63\%), nodular (25\%), grid-like (13\%), patchy (11\%), crazy-stones-like (4\%), honey-comb (4\%), lumpy (1\%), with interlobular septal thickening in $6 \%$, consolidation in $75 \%$, accompanied by air-bronchograms (10\%), bronchiectasis/atelectasis (10\%), pleural effusion (39\%), pericardial effusion (14\%), mediastinal lymphonodes (49\%) (Figures $3 \mathrm{a}$ and $3 \mathrm{~b}$ ). Honey-comb aspects were observed only in lymphopenic patients, pleural effusion mainly in these ones, air-bronchograms in all non-survivors. Comorbidity with emphysema was present in $40 \%$ of non-survivors without lymphopenia, $60 \%$ of non-survivors with lymphopenia. Control chest $\mathrm{Rx} / \mathrm{TC}$ showed clear evidences of worsening in 19/72 (26\%), stability in 11/72 (15\%), improvement in $36 / 72(50 \%)$ patients. Nine patients $(10 \%)$ died, 8/89 (9\%) showed clinical improvement and were transferred/ discharged before control Rx/TC. In the other patients, new lesions were concomitantly present with aspects of improvement of older ones. Improvement was present in imagings of 15/30 (50\%) lymphopenic survivors (group $\mathrm{Aa}$ ) and $0 / 16(0 \%)$ non-survivors $(\mathrm{Ab})$, in $19 / 29$ (66\%) survivors (group $\mathrm{Ba}$ ) and 2/9 (22\%) non-survivors (Bb), without lymphopenia. Worsening was described in 7/30 (23\%) Aa, 9/16 (56\%) $\mathrm{Ab}, 0 / 29(0 \%) \mathrm{Ba}, 3 / 9$ (33\%) Bb. Peripheral, deep arterial or venous thrombosis was detected in 4/89 (4\%), pulmonary thromboembolism in $3 / 89(3 \%)$ (Figure 3).Comorbidities were arterial hypertension $(63 / 89,71 \%)$, chronic cerebrovascular disease $(27 / 89,30 \%)$, chronic coronary syndrome $(24 / 89,27 \%)$, atrial fibrillation (19/89, $21 \%)$, type II diabetes mellitus $(19 / 89,21 \%)$, chronic obstructive pulmonary diseases $(18 / 89,20 \%)$, vascular or mixed dementia $(18 / 89,20 \%)$, obesity $(16 / 89$, $18 \%)$, outcomes of acute strokes $(10 / 89,11 \%)$, neoplasia $(7 / 89,8 \%)$, 
chronic renal failure $(5 / 89,6 \%)$, Parkinson's disease $(4 / 89,4 \%)$, chronic psychosis $(4 / 89,4 \%)$, surgically treated hip racture $(2 / 89,2 \%)$, nosurgical treated hip fracture $(1 / 89,1 \%)$ (Figure 4$)$.

First oro-pharyngeal and/or nasal swab was positive for Cov2 RNA in $64 / 89(72 \%)$ patients. A second swab was necessary in $8 / 89(9 \%)$ patients to confirm the diagnosis. In $5 / 89(6 \%)$ patients the diagnosis was confirmed by the presence of IgM anti-CoV2 at rapid test. In 10/89 (11\%) both swab and rapid test were negative, although clinical and radiological findings were highly suggestive of ongoing SARS Cov2. Two patients died before undergoing diagnostic procedures.
At admission, blood cell counts showed absolute lymphopenia $(0,8$ sd $0,27 \times 10^{3}$ ) in 46/89 (52\%), accompanied by neutrophilia, suggesting possible superimposed bacterial infections. Brescia Covid Scale was tendentially higher in lymphopenic, survivors (Aa) and non-survivors $(\mathrm{Ab})$, compared with patients without lymphopenia, survivors $(\mathrm{Ba})$ and non-survivors (Bb) (Aa 0,7 sd 1,06, Ab 1,33 sd 2,19, Ba 0,38 sd 1,05, Bb 0,75 sd 1,04) (Figure 5).

At intergroup analysis, there were a tendency to higher levels of $\mathrm{C}$ Reactive Protein (CRP) (74,46 sd 73,27 vs 50,6 sd 70,88), procalcitonin (PCT) $(0,45$ sd 1,92 vs 0,25 sd 0,53), d-dimer (d-dim) (4,46 sd 133,07

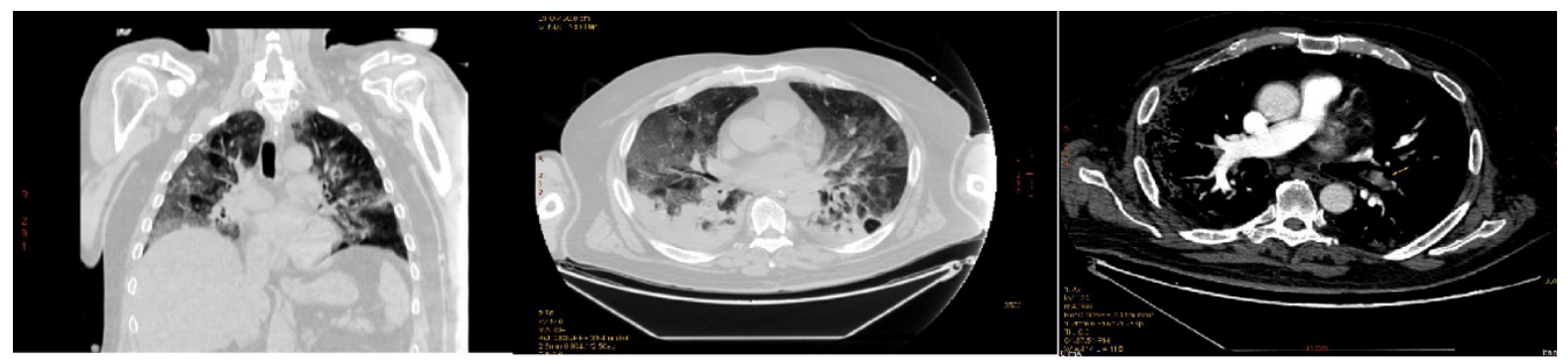

Figure 3. Coronal (left) and axial (right) chest CT imagings in a 63 years old, male patient, affected with SARS-CoV2. (C)Thrombo-embolic aspect (arrow) in an axial chest CT imaging with contrast in a 63 years old, male patient, affected with SARS-CoV2

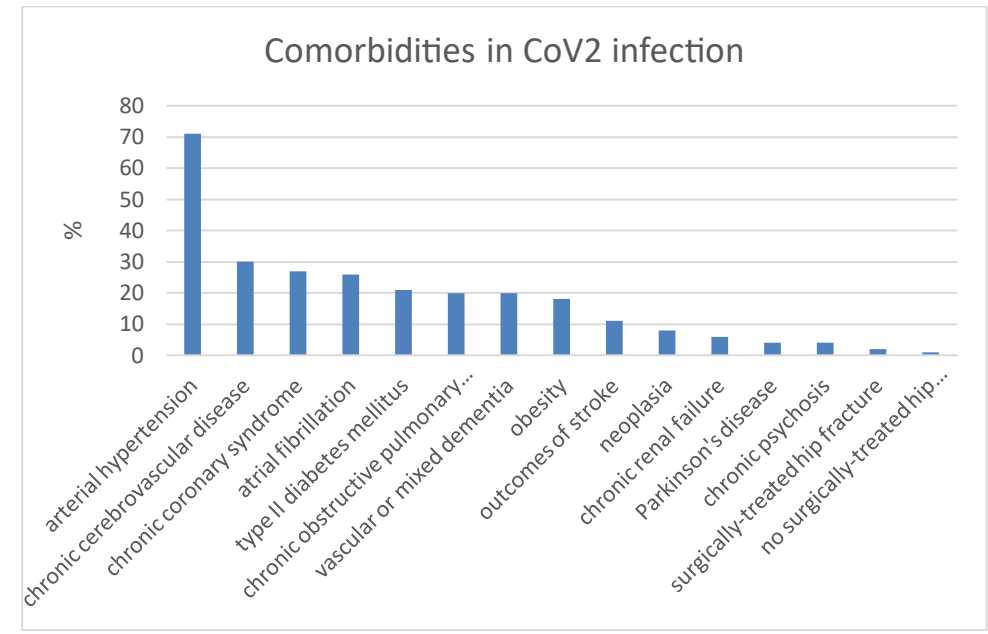

Figure 4. Percentage of patients with comorbidities in CoV2 infections

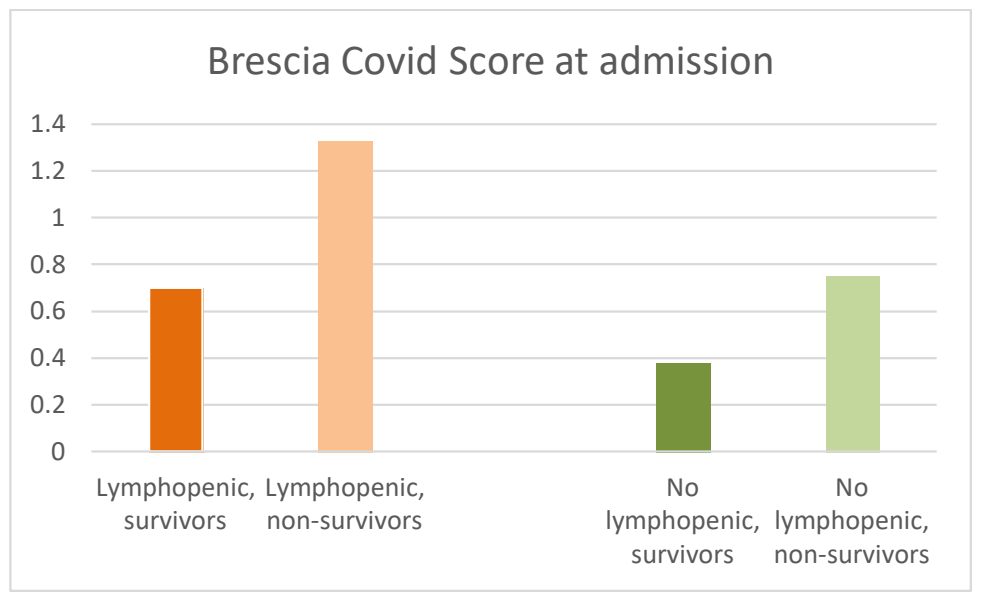

Figure 5. Brescia Covid Score at admission in lymphopenic, survivors and non-survivors (left), no lymphopenic, survivors and non-survivors (right) 
vs 1,63 sd 2,61), hs-troponin (hs-tro) (226,6 sd 1252,98 vs 62,99 sd $148,55)$ in A compared to B. Haematological parameters in subgroups of patients (Aa vs $\mathrm{Ab}, \mathrm{Ba}$ vs $\mathrm{Bb}$ ) at admission (1) and at the last control (2) are shown in the Table 1.

At intragroup analysis, there was a decrease of CRP at the last control compared to admission (Aa1 vs Aa2, p 0,03; Ba1 vs Ba2, p 0,01) in all survivors (Figure 6). A tendency to higher CRP was detected in Ab2 (p 0,07). An increase in PCT was revealed both in Ab2 (p 0,01) and $\mathrm{Bb} 2$ (p 0,007) (Figure 7). Absolute lymphocyte counts decreased in $\mathrm{Bb} 2$ (p 0,08), while it increased in Aa2 (p 0,002) (Figure 8).

In non-survivors, Brescia Covid Score correlated with absolute lymphocyte count (Ab r -0,53, Bb r -0,31), creatinine (Ab r 0,29, Bb r 0,49), $\mathrm{pH}(\mathrm{Ab} \mathrm{r}-0,68, \mathrm{Bb} \mathrm{r}-0,49), \mathrm{HCO}_{3}$ ( $\mathrm{Ab} \mathrm{r} \mathrm{-0,62,} \mathrm{Bb} \mathrm{r} \mathrm{-0,50),} \mathrm{SaO}_{2}$ (Ab r -0,82, Bb r -0,79), P/F (Ab r -0,71, Bb r -0,53).

Antiviral therapy was administered in $43 / 89$ (48\%) patients: $23 / 89$ (26\%) received lopinavir/ritonavir 200/50 mg 2 tablets, twice/daily, 20/89 (22\%) darunavir $800 \mathrm{mg} /$ ritonavir $100 \mathrm{mg} 1$ tablet, daily. Seventy patients (79\%) were treated with hydrossiclorochine $200 \mathrm{mg} 1$ tablet, twice/daily. Five patients (6\%) were treated with baricitinib $4 \mathrm{mg}, 1$ tablet/daily, $2(2 \%)$ with tocilizumab $8 \mathrm{mg} / \mathrm{kg}$ in $100 \mathrm{ml}$ physiologic solution, in 60 minutes, every 12 hours, 2-3 times. Remdesivir was not available. Forty-six patients (52\%) were treated with steroids (dexamethasone 8-16 mg/daily, methylprednisolone 20-40 mg/daily, iv). All the above therapies, except for tocilizumab, were administered for 7-10 days. The dose of steroids was increased at dyspnea exacerbation. All but one patient received low molecular weight heparin (enoxaparin) at the dose of $4000 \mathrm{IU}$, in patients affected with thromboembolism the dose was doubled, and in two of those patients the dose was increased up to $6000 \mathrm{IU} \times 2$. Vitamin D was added in $34 / 89$ patients (38\%). Antipyretic therapy, proton pump inhibitors, antibiotics, hydration and nutritional support were administered according to patient's needs. Neither significant results, nor side effects were observed specifically related to pharmacological therapies. Respiratory exercises were recommended to favor remission, especially in juvenile cases, while they were scarcely effective in non-collaborating, elderly patients. Oxygen was administered through nasal cannula. Venturi mask $\left(\mathrm{O}_{2}\right.$ flow from 2 to $15 \mathrm{l} / \mathrm{min}$ ) was necessary in 41/89 (46\%). In a minority of patients $(9 / 89,10 \%)$, Non-Invasive-Positive Pressure-Ventilation (NIPV) was necessary $(\mathrm{SaO} 2<90 \%, \mathrm{PaO} 2<60 \mathrm{mmHg}, \mathrm{FiO} 2 \mathrm{PaO} 2 /$

Table 1. Haematological parameters in lymphopenic and no lymphopenic patients

\begin{tabular}{|c|c|c|c|c|c|c|}
\hline \multicolumn{7}{|l|}{ LYMPHOPENIC } \\
\hline & SURVIVORS & NON-SURVIVORS & & SURVIVORS & NON-SURVIVORS & \\
\hline & \multicolumn{2}{|c|}{ First withdrawal } & & \multicolumn{2}{|c|}{ Last withdrawal } & \\
\hline $\mathrm{CRP}(\mathrm{mg} / \mathrm{L})$ & 54,81 sd 58,69 & 121,77 sd 85,47 & p 0,006 & 22,37 sd 50,64 & 196,93 sd 95,15 & \\
\hline PCT (ng/ml) & 0,08 sd 0,08 & $1,34 \mathrm{sd} 3,52$ & $p 0,06$ & $1,07 \mathrm{sd} 4,02$ & $6,15 \operatorname{sd} 8$ & \\
\hline White Blood Cells (n x 103) & 5322,67 sd 2121,28 & $6535 \mathrm{sd} 3615,65$ & & 8355,46 sd 10919,16 & $7139,17 \mathrm{sd} 4035,61$ & \\
\hline Absolute Lympnocyte Count (n x 103) & 810,47 sd 278,94 & 793,13 sd 273,56 & & 1682,89 sd 1451,64 & 724,17 sd 636,32 & $p 0,03$ \\
\hline d-dimer $(\mathrm{mg} / \mathrm{L})$ & 2,79 sd 4,74 & 10,18 sd 18,42 & p 0,07 & $1,04 \mathrm{sd} 1,54$ & 5,44 sd 8,29 & $p 0,02$ \\
\hline hs-Troponin (ng/L) & 91,3 sd 5,48 & $734,04 \mathrm{sd} 2272,63$ & p 0,09 & 16,48 sd 30,06 & 51,4 sd 1,01 & \\
\hline Creatinine (mg/dl) & $0,93 \operatorname{sd} 0,29$ & $1,45 \operatorname{sd} 0,89$ & $p 0,006$ & 0,88 sd 0,28 & $2,1 \mathrm{sd} 1,58$ & p 0,0005 \\
\hline \multicolumn{7}{|l|}{ NO LYMPHOPENIC } \\
\hline & SURVIVORS & NON-SURVIVORS & & SURVIVORS & NON-SURVIVORS & \\
\hline & First withdrawl & & & Last withdrawal & & \\
\hline CRP (mg/L) & 50,77 sd 77,05 & $49,97 \mathrm{sd} 45,7$ & & 5,09 sd 5,98 & 34,3 sd 40,81 & $p 0,005$ \\
\hline PCT (ng/ml) & 0,26 sd 0,56 & $0,15 \operatorname{sd} 0,21$ & & $0,04 \mathrm{sd} 0,04$ & 3,32 sd 1,44 & \\
\hline White Blood Cells (n x 103) & $8232,414552,98$ & $10623,33 \mathrm{sd} 4034,49$ & & $6258,95 \mathrm{sd} 2373,51$ & 6602,99 sd 3538,9 & \\
\hline Absolute Lympnocyte Count (n x 103) & $1746,17 \mathrm{sd} 472,30$ & $1724,44 \mathrm{sd} 422,58$ & & 1795,96 sd 672,79 & $1147,14 \mathrm{sd} 815,24$ & $p 0,05$ \\
\hline d-dimer $(\mathrm{mg} / \mathrm{L})$ & $1,1 \mathrm{sd} 1,12$ & $3,64 \mathrm{sd} 4,92$ & & $3,98 \mathrm{sd} 12,07$ & $2,97 \mathrm{sd} 3,86$ & \\
\hline hs-Troponin (ng/L) & 44,11 sd 99,79 & 130,4 sd 260,48 & & 12,5 sd 22,5 & 29,03 sd 23,18 & \\
\hline Creatinine (mg/dl) & 0,86 sd 0,33 & $1,51 \mathrm{sd} 0,68$ & $p 0,0004$ & 0,84 sd 0,19 & 1,66 sd 1,73 & $p 0,05$ \\
\hline
\end{tabular}

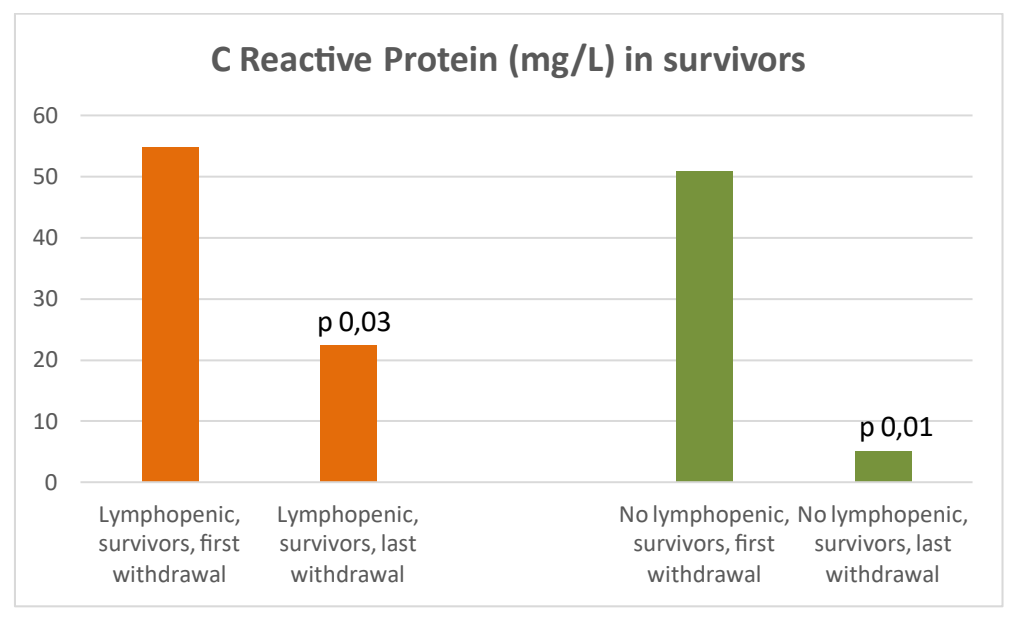

Figure 6. CRP (mg/L) in lymphopenic (left) and no lymphopenic (right) survivors 


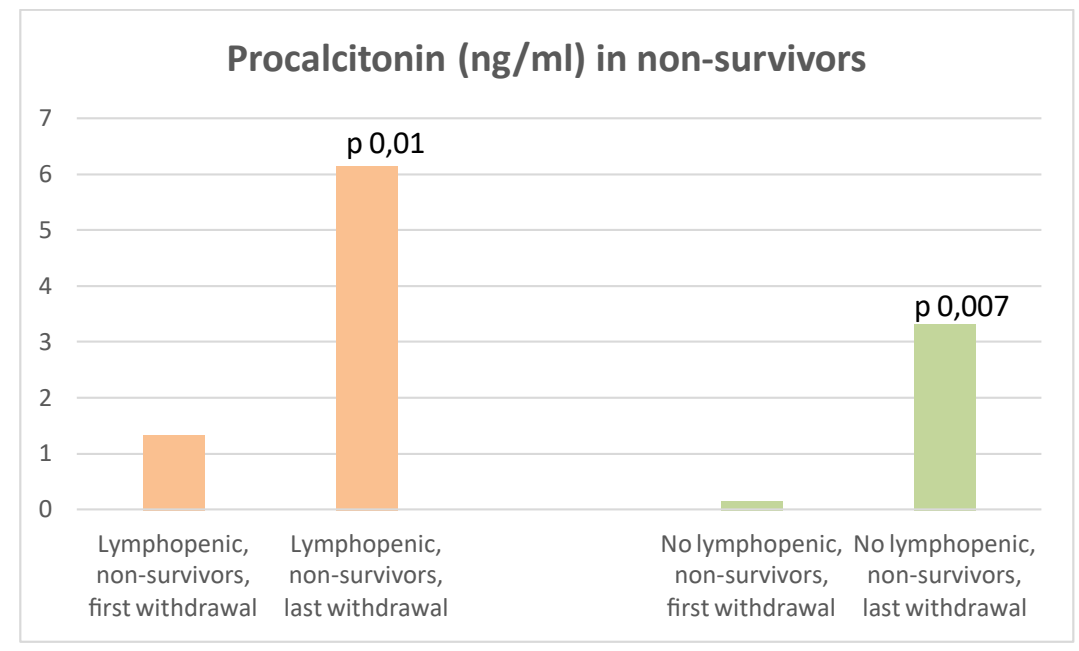

Figure 7. PCT (ng/ml) in lymphopenic (left) and no lymphopenic (right) non-survivors

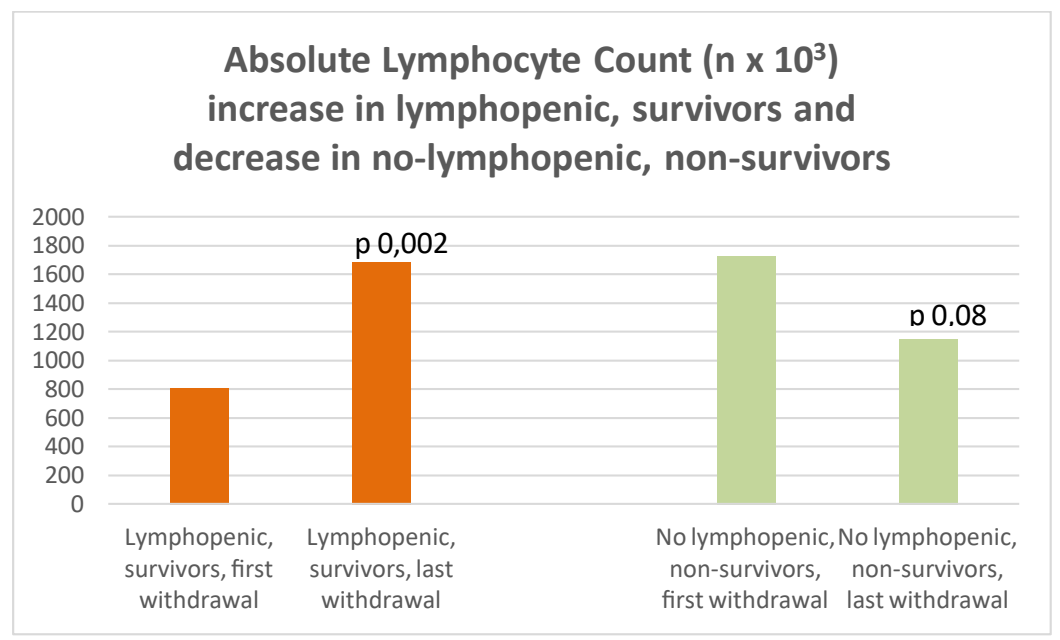

Figure 8. Absolute Lymphocyte Count $\left(\mathrm{n} \times 10^{3}\right)$ in lymphopenic survivors (left) and no lymphopenic non-survivors (right)

FiO2 101-200 mmHg). In 4/89 (4,5\%) cases $(\mathrm{SaO} 2<90 \%, \mathrm{PaO} 2$ $<60 \mathrm{mmHg}$, FiO2 $\mathrm{PaO} 2 / \mathrm{FiO} 2 \leq 100 \mathrm{mmHg}$ ), it was followed by prone position and transfer to intensive care unit for invasive oxygen therapy (IOT) through endotracheal intubation. Tidal volume (4$6 \mathrm{ml} / \mathrm{kg})$, low plateau pressure $\left(<30 \mathrm{cmH}_{2} \mathrm{O}\right)$, and appropriate PEEP $\left(>5<15 \mathrm{cnH}_{2} \mathrm{O}\right)$ were established. Oxygen therapy was effective in maintaining $\mathrm{O}_{2}$ levels both in patients without and with lymphopenia, while in the latter there was a tendency to higher level of $\mathrm{CO}_{2}$. At the last control, haemogasanalysis showed the following significant differences: $\mathrm{Ba} 2$ vs $\mathrm{Bb} 2$ : $\mathrm{HCO} 329,1$ sd 3,55 vs 22,97 sd 4,75, p 0,01; Aa2 vs Ab2: ph 7,46 sd 0,03 vs 7,22 sd 0,23 (p 0,0003), pCO2 38,63 sd 11,06 vs 55,6 sd $39,53, \mathrm{HCO} 325,64$ sd 3,88 vs 17,65 sd $5(0,002), \mathrm{SaO} 2$ 95,98 sd 2,92 vs 82,84 sd 28,66 (p 0,07), P/F 366 sd 95,95 vs 177,8 sd 40,54 (p 0,0004) (Figure 9).

An attempt of decapnization was performed in one patient by Prolung Meter ESTOR system.

Mean length of hospitalization was 17,83 sd 14,18 days. Overall mortality was $30 \%$ (27/89 patients). It was higher in males $(18 / 89,20 \%)$ compared to females $(9 / 89,10 \%)$. It was $20 \%$ in $>80$ years old $(18 / 89$ patients), $7 \%$ in $65-80$ years old $(6 / 89 \%), 3 \%$ in $35-65$ years old $(3 / 89$ patients), $0 \%$ in $<35$ years old patients (Figure 10 ). It was $21 \%$ in patients with lymphopenia compared to $9 \%$ in those without lymphopenia (Figure 11). Although PCT levels and neutrophilia suggested superimposed bacterial infection, cultures resulted positive only in a minority of patients: 5/89 (6\%) haemoculture (Staphylococcus epidermidis and aureus, group F Streptococcus, Escherichia coli, Enterococcus faecalis, Candida albicans), 6/89 (7\%) urinocolture (Escherichia coli, Staphylococcus spp, Enterococcus faecalis, Clostridium difficile), 1/89 (1\%) oro-pharyngeal and nasal swab (Staphylococcus epidermidis and haemolyticus), 1/89 (1\%) sputum (Enterococcus faecalis), 1/89 (1\%) bronchoaspirate (Pseudomonas aeruginosa), 1/89 (1\%) decubitus ulcer (Staphylococcus aureus, Escherichia coli). Mortality was attributed to sepsis in one case (Pseudomonas aeruginosa), cardio-respiratory arrest in multi-organ failure in the other patients.

Thirty-four of eighty-nine (38\%) patients were discharged, 3/89 (3\%) were transferred to other intensive care unit for infectious diseases, 25/89 (28\%) to nursing home (Figure 12).

On the bases of our results, we propose the following CoV2 Prognostic Scale (CVPS) (Table 2). Significant differences in CVPS score were present between $\mathrm{Aa}$ vs $\mathrm{Ab}$ (7,4 sd 2,4 vs 9,5 sd 1,9, p 0,003) and $\mathrm{Ba}$ vs $\mathrm{Bb}(4,9$ sd 2,7 vs 6,7 sd 1,3, p 0,03). 


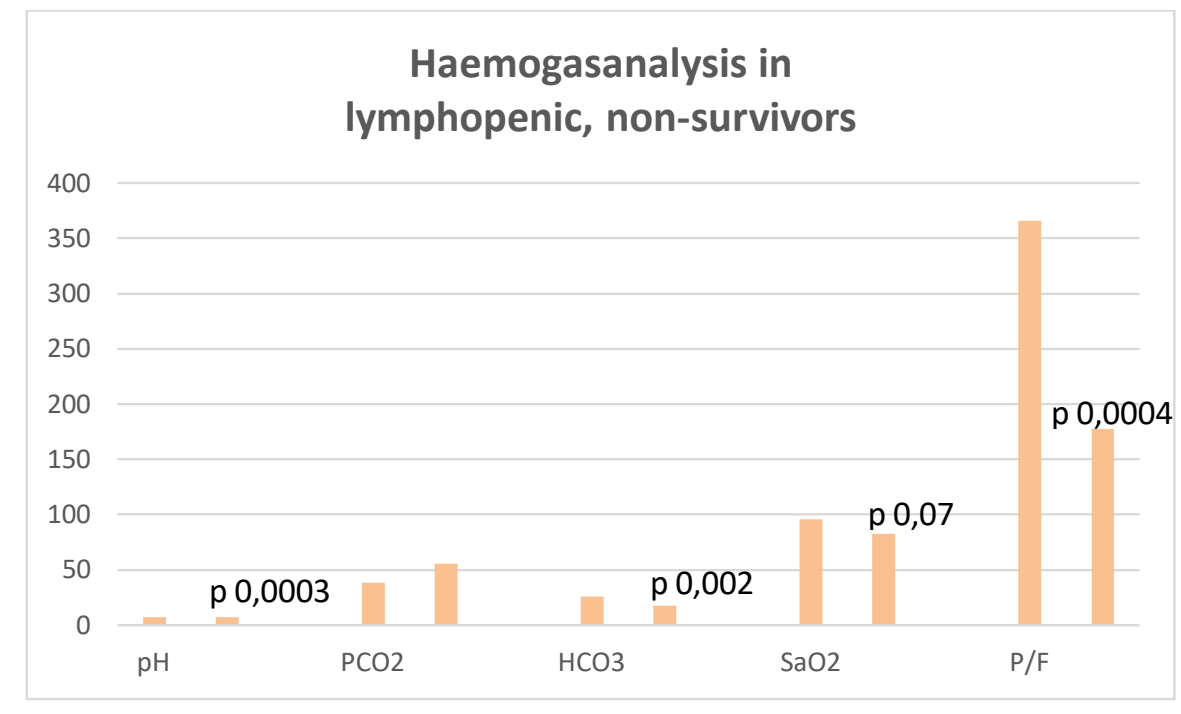

Figure 9. Haemogasnalysis in lymphopenic, non-survivors

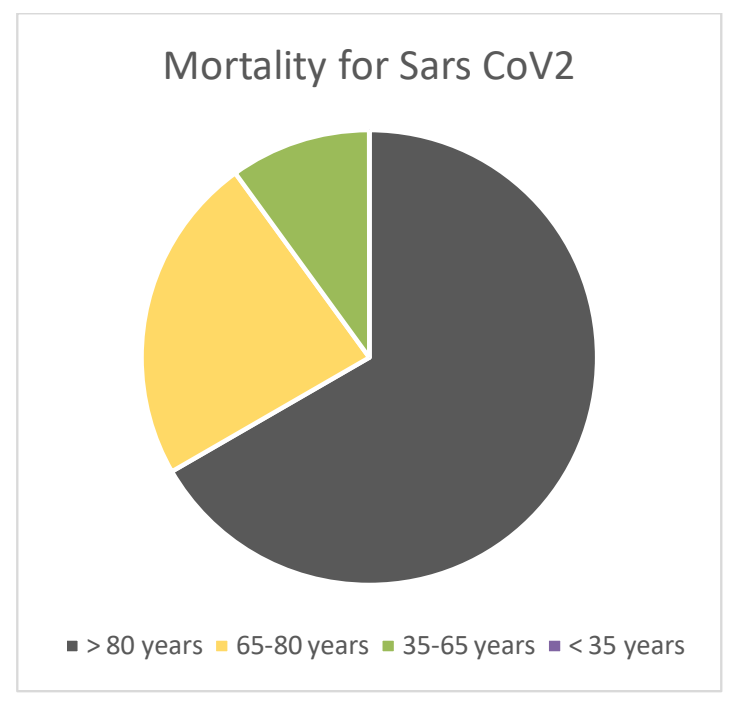

Figure 10. Mortality for SARS CoV2 in > $80(20 \%), 65-80(7 \%), 35-65(3 \%),<35(0 \%)$ years old patients

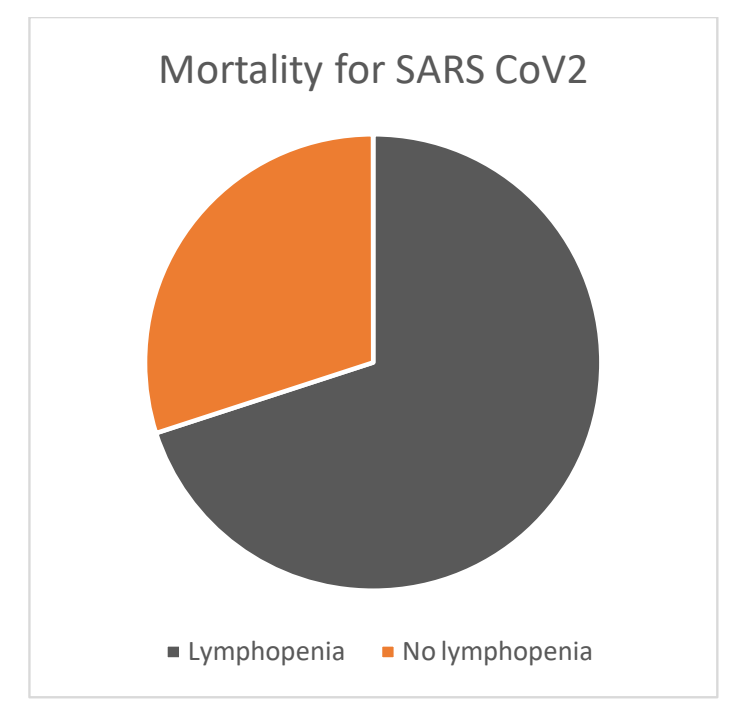

Figure 11. Mortality for SARS CoV2 in lymphopenic (21\%) and no lymphopenic (9\%) patients 


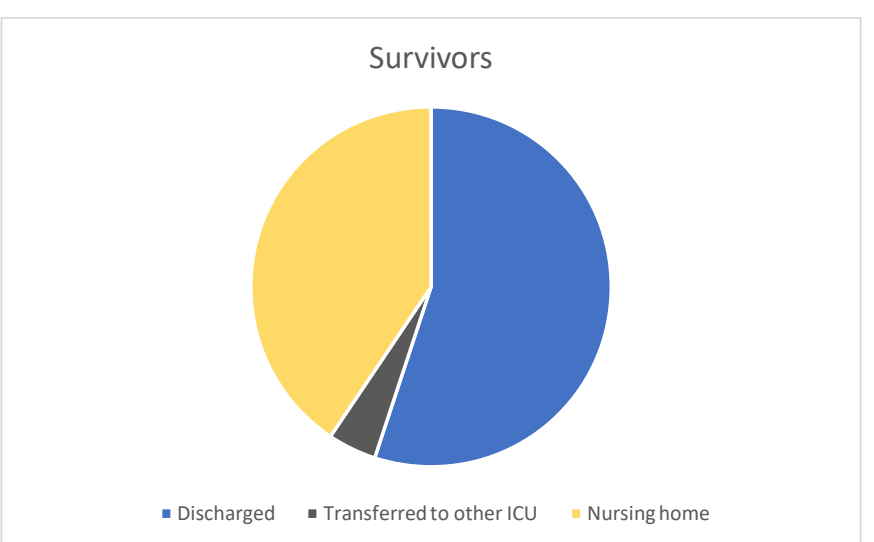

Figure 12. Discharged (38\%), transferred to other ICU (3\%), to nursing home survivors $(28 \%)$

Table 2. CoV2 prognostic scale

\begin{tabular}{|c|c|c|}
\hline & $\begin{array}{c}\text { CoV2 PROGNOSTIC } \\
\text { SCALE }\end{array}$ & \\
\hline Age & $>80$ years & 2 \\
\hline Sex & 65-80 years & 1 \\
\hline & Male & 2 \\
\hline Arterial Hypertension & Female & 2 \\
\hline Type II diabetes mellitus & & 1 \\
\hline Chronic Cerebrovascular & & 1 \\
\hline Diseases & & 1 \\
\hline Chronic Coronary Syndrome & & 2 \\
\hline Pulmonary emphysema & & 2 \\
\hline Chronic Renal Failure & & 2 \\
\hline Lymphocytopenia & & max 17 males \\
\hline Superimposed infections & & max 16 females \\
\hline
\end{tabular}

\section{Discussion}

Although the incidence of CoV2 SARS was high, the mortality was inferior compared to the north of Italy. This was explained by early diagnosis and therapy in admitted patients and screening on all the inhabitants. Low level of environmental pollution contributed to reduced morbidity and better outcomes. Comorbidities in elderly patients negatively interfered with recovery and weighted on the pathological process leading to the exitus. Blood cell counts, together with specific immunological test, may easily discriminate between immune-depressed, highly-contagious and immune-competent, lowcontagious subjects. Nosocomial isolation is crucial for the former. The latter may be early discharged and home-treated, if pauci- or asymptomatic.

The negativity of rapid test may include false negative. Moreover, as acutely observed [22], oro-pharyngeal swab detects the presence of viral RNA, not alive virus. Its negativity does not exclude ongoing infection. The diagnosis must be based on clinical and radiological findings before invasive procedures, as broncho-aspiration and broncho-lavage. These may confirm low respiratory infection, but they are risky, because of potential iatrogenic viral diffusion, and dangerous because of possible mucosal injury. An alternative may be represented by plasma biomarkers of epithelial (surfactant protein-D, soluble Receptor for Advanced Glycation End Products) and endothelial injury
(Angiopoietin 2, Intracellular Adhesion Molecule 1). A metanalysis showed that high plasma levels of Angiopoietin 2 and Receptor for Advanced Glycation End Products were associated with an increased risk of Acute Respiratory Distress Syndrome development [23]. IOT in elderly patients is a difficult task because of the heterogeneity of individual pathological findings. Weaning from invasive to non-invasive ventilation is even more arduous. Because of basal, reduced thoracic excursion, gas exchange is impaired, $\mathrm{CO} 2$ levels are high and $\mathrm{O} 2$ supply may be unsuccessful. Ventilator-associated/ventilator-induced lung injury (barotrauma, volutrauma, atelectrauma, biotrauma) seem to be more related to acute necrosis and underlying apoptosis rather than to applied techniques. Indeed, alveolar epithelial and endothelial damage, immune-dysregulation, intravascular coagulation, neuro-muscular and cardiological impairment may cause brief and long-term pulmonary dysfunction, leading to fibrosis in case of survival, irreversible pulmonary failure, death.

Plasma levels of CRP, PCT and cytokines, as Interleukin 6, may be useful for monitoring the course of the disease. However, the inflammatory cascade may be followed by lymphocyte exhaustion and immune-depression. Microbiota and innate humoral immune response, firstly represented by mucosal IgA production by $\mathrm{B}$ lymphocyte, are the first line of host defense. They play a pivotal role in limiting viral anchorage and invasion. The activation of viral sensors, as system of pattern recognition receptors generates a positive feedback loop, recruiting immune cells, stimulating cytokine production [24]. Specific humoral and cellular immunity, cytokine storm and natural killer cytotoxicity may quickly eliminate the virus. If humoral immune response fails and adaptive immune response against CoV2 does not mount and/or is overwhelmed by viral persistence and CoV2 succeed in hijacking the host cellular machineries, tissular damage occurs. Autoimmune reactions may be triggered and may worsen the clinical picture. Apoptosis may be observed, as host response to limit viral replication. This may involve not only respiratory tract, but also mucosal, intestinal, kidney tubular, neuronal, immune cells, leading to loss of immune-competence, viral spreading and diffuse organ dysfunction [25]. Genetic factors may predispose to the disease. Lymphopenic state or lymphocyte exhaustion may account for infection with other agents or reinfection with $\mathrm{CoV} 2$, loss of tolerance, activation of autoimmune cells because of molecular mimicry, epitope spreading and bystander activation [22]. SARS-CoV2 epitopes shares homologies with human heat shock proteins [26] and brainstem respiratory pacemaker [27]. Moreover, strong immune cross-reaction was found between spike protein antibodies and parenchymal proteins, as pulmonary surfactant, mitochondrial proteins and myelin basic protein [28-30]. The duration, the magnitude, the type and the term memory of immune protection are unknown. It is also conceivable that host-virus interaction may result in a latent "cold-war", which may attenuate or reinforce virulence, according to genetic factors and immunological asset. The disease may evolve toward a chronic, progressive, multi-organ parenchymal damage and pulmonary thrombo-embolisms. The presence of non-neutralizing or sub-neutralizing concentrations of anti-Cov2-antibodies, may cause an antibody-dependent enhancement (ADE) of viral infection and replication by antibody interaction with cell surface Fc receptors, virus-antibody immune complexes internalization, virion uncoating and release of viral genome in the cytoplasm. The antiviral immune response itself may be downregulated by altered host intracellular signaling pathway. Memory to cross-reactive antigens may have been elicited by previous other coronavirus infection ("original antigenic sin") and account for both less effective, specific immune response to $\mathrm{CoV} 2$ and ADE. On the other hand, naïve, specific immune response 
may efficiently defend children from severe disease. It is still not known whether the anticipatory immunity plays a pivotal role against CoV2 and trained immunity is protective [31].

Radiological findings suggest that consolidations represent frank, inflammatory foci. The peculiar ground-glass areas may be the expression of early microvascular involvement, followed by necrotic phenomena, with possible faster, further evolution toward honey-comb and reticular aspects of fibrosis. In order to prompt decision making on treatments, the key for correct imagings' interpretation is firstly defining the prevalent emphysematous-like or congestive-like pattern, especially in elderly patients. The presence of halo sign may represent peripheral oedema in still savable tissue (penumbra), surrounding the parenchymal lesion. Reversed halo sign may be predictive of worst prognosis because of an ischaemic core with ongoing, peripheral, inflammatory progression. Once resolved, bubble sign may remain. In some patients, the ground-glass lesions may be more evident peripherally (subpleural location) in early phase, because of vasculitis in microvessels, followed by proximal parenchymal extension in fullblown disease. In elderly, lymphopenic patients, the inflammatory picture may paradoxically and apparently be less severe, because of early alveolar loss and rarified pulmonary structure.

CoV2 has multiple targets. Beside non-specific complications of systemic disease, viral spreading may cause peculiar, organ-specific, clinical pictures. Central Nervous System may be involved by direct haematogenous diffusion or through retrograde neuronal route, infectious and para-infectious pathological phenomena, generating a cascade of deleterious, organ-specific and systemic impairment with brief and long-term sequelae [32]. Similar to immune cells, sensory neurons express receptors for pathogen-associated molecular pattern. Inflammatory responses may perturb neuronal activities and elicit pathological reflexes [33]. Both acute and chronic respiratory failure may accentuate neuropsychiatric features, cause acute strokes and accelerate the onset of neurodegenerative diseases [34]. Younger age, embolic genesis, worse prognosis were described in stroke patients [35]. Anti-phospholipid antibodies were detected [36]. Guillan-Barrè like syndrome in CoV2 patients may rapidly evolve to respiratory failure. Cases of lacunar strokes, acute necrotizing encephalitis, seizures, meningo-encephalo-myelitis, myasthenic signs and rhabdomyolisis are reported. The presence of neurological signs worsens the clinical picture of SARS-CoV2, as shown by altered haematological parameters [37]. Hypercoagulable/hyperviscosity state is present. Inflammation in microvessels may result in lacunar ischaemic sufferance and large infarction, because of plaque vulnerability and myocardial damage [38]. The same pathological mechanisms may account for cardiological dysfunctions, mainly represented by acute coronary syndrome and arrhythmias. The latter may be recorded in case of myocarditis, caused by direct viral injury, and be iatrogenic, induced by chloroquine or hydroxychloroquine. Dilated cardiomyopathy and heart failure may ensue [39]. Renal involvement, ranging from mild-moderate proteinuria to acute renal failure, further worsen clinical conditions and may be linked to poor prognosis, long-term complicances and death [40]. These are related to direct viral infection, inflammation, hypercoagulation, volume depletion, heart and respiratory failure, rhabdomyolysis. Beside tubular, we suspect early, acute, glomerular damage.

Current knowledge on CoV2 multiorgan damage is still partial. Reduced number of patients come to observation in emergency unit for fear of CoV2 contagion. Acute neurological as well as cardiological patients are directly transferred to non-CoV2 units. CoV2 related dysfunctions may be misdiagnosed because of previous positive case history of organ impairment and non-urgent examinations are postponed for reducing the risk of in-hospital cross-infection. On the other hand, the delay in diagnosis of all the other diseases endangers public health.

Immune-depressed patients, affected with severe diseases may be more vulnerable also to low viral load, become intermediate reservoirs of more virulent $\mathrm{CoV}$, as suggested by nosocomial outbreaks and poor prognosis. Indeed, lymphopenia is observed at admission and reported in full blown disease $[41,42]$ as well as an increased risk of coinfections [43]. Moreover, both morbidity and lethality increase by aging.

In immunocompetent subjects, human to human transmission may be linked to high viral load, stressors, as hard work shifts, smoking, alcohol or other substance abuse, unhealthy behaviors [44], subsequent increased disease susceptibility, plausibly followed by immune-defiance, as suggested by disease clusters in seafood, wet market workers in China, slaughterhouse workers in Deutschland, express couriers in Italy. The stress gateway reflex induces cerebral micro-inflammation, excites neural pathways, disturbing functions of organs in the periphery [33]. Viral load, mutagenesis rate, crossing of species barrier are expression of contagion and diffusion in high density population, in case of extreme social and economic gap, urbanization, poor hygiene conditions, as in rural farming [45], paucity of environmental resources, conflicts, migrations, climate changes and environmental disasters. These may represent a Damocles' sword for future generation, if shared rules are not respected.

The ability to recombine using both homologous and nonhomologous recombination is known to favor viral evolution and virulence [46,47]. CoVs are recognized among the most rapidly evolving viruses, owing to their high genomic nucleotide substitution rates and recombination, antigenic drift and shift [48]. This may hinder the production of an effective vaccine or render it useless. On the other hand, higher the viral homology, more likely the immune cross-reactivity develops. Neutralizing antibodies may be produced in experimental animals and administered during acute phase, but the risk of thrombotic events may be further increased as well as the antibody-dependent enhancement of viral infection. The latter risk may be reduced by substitution or removal of viral enhancing epitopes. Alternative biotechnological approaches may be blockage of viral anchorage by soluble receptor binding domains of S protein, antibody or single chain antibody fragment against ACE2, target the coronavirus virions directly by using the ACE2 extracellular domain binding the spike protein (ACE2-Fc construct). Lastly, small interfering RNA (siRNA) or antisense oligonucleotides (ASO) to combat the virus by targeting its RNA genome may be generated [49]. However, the availability of these therapies may be limited because of the high cost of production. Administration of antiviral agents may be limited. An affordable therapy may be plasma infusion. It is unknown whether asymptomatic subjects are "super-spreaders", although their immunologic system actively fight and defeat viral attack, reducing virulence more efficiently than any other available drug. They may represent the ideal plasma donors, because of polyclonal antibody immune response to different viral antigens, devoid of autoimmune bioproducts. The study of herd immunity may highlight the mechanisms of immune-resistance. The latter may be overcome by environmental contamination. Beside respiratory droplets, self-inoculation, if hygienic procedures are not respected, and shedding by infectious materials (sputum, fecis, blood) may occur [50]. It is reported that CoV2 resists on surface (aerosol 3 hours, copper 4 hours, cardboard 24 hours, plastic 2-3 days, stainless 2-3 days) [51]. Although, CoVs seem to be able to 
persist in the environment up to 9 days, they can be inactivated within one minute by disinfection with ethanol, hydrogen peroxide, sodium hypochlorite [52]. Then, the viral load is presumably proportional to immune-depression in amplifying hosts.

\section{Conclusions}

Advanced age, comorbidities, lymphocytopenia and bacterial superimposed infections are red flags predicting worse prognosis in SARS CoV2. Healthy behavioral habits safeguard young and middle age subjects from the disease. The most powerful strategy for disease eradication is health education. It is mandatory not to disappoint trust on health care. Elementary rules, as use of caps, googles, gloves, washing hands, disinfecting surface, avoiding crowds and travel, social distancing are important for limiting the risk of infection. Home confinement and lockdown are extreme measures which must be rationally applied, because of long-term deriving economic crisis, due to reduction of gross national product, low tax incomes, need to ensure social support to indigent people, insurmountable account deficit. Protective devises for health care providers must be smartly used, because they are not ecologically disposable. Green (no-contaminated) and red (contaminated) paths must be clearly marked and only health care personnel, charged of daily clinical evaluation of patients, must be adequately dressed. Because of pleiomorphic clinical and radiological findings, it would be better to avail tests for the simultaneous detection of common viral and bacterial agents for the most appropriate therapy, as multiplex PCR array. CoV2 Prognostic Scale may speed up decision making on clinical setting and treatments. International cooperation is fundamental for a rational, concerted action directed to safeguard public health and reduce the impact on socio-economical asset.

\section{Conflict of interests}

None.

\section{Acknowledgements}

We thank Dr. Monaco Armando, computer engineer.

\section{References}

1. Ksiazek TG, Erdman D, Goldsmith CS, Zaki SR, Peret T, et al. (2003) A novel coronavirus associated with severe acute respiratory syndrome. $N$ Engl J Med 348: 1953-1966. [Crossref]

2. de Groot RJ, Baker SC, Baric RS, Brown CS, Drosten C, et al. (2013) Middle East respiratory syndrome coronavirus (MERS-CoV): announcement of the coronavirus study group. J Virol 87: 7790-7792. [Crossref]

3. de Wit E, van Doremalen N, Falzarano D, Munster VJ (2016) SARS and MERS: recent insights into emerging coronaviruses. Nat Rev Microbiol 14: 523-534. [Crossref]

4. Peiris JSM, Lai ST, Poon LLM, Guan Y, Yam LYC, et al. (2003) Coronavirus as a possible cause of severe acute respiratory syndrome. Lancet 361: 1319-1325.

5. Zaki A.M, van Boheemen S, Bestebroer TM, Osterhaus A, Fouchier RAM (2012) Isolation of a novel coronavirus from a man with pneumonia in Saudi Arabia. $N$ Engl J Med 367: 1814-1820.

6. Lu R, Zhao X, Li J, Niu P, Yang B, et al. (2020) Genomic characterization and epidemiology of 2019 novel coronavirus: implications for virus origins and receptor binding. Lancet 395: 565-574. [Crossref]

7. de Wilde AH, Snijder EJ, Kikkert M, van Hemert MJ (2018) Host factors in coronavirus replication. Curr Top Microbiol Immunol 419: 1-42.

8. Hoffmann M, Kleine-Weber H, Krüger N, Müller M, Drosten C, et al. (2020) The novel coronavirus 2019 (2019-nCoV) uses the SARS-coronavirus receptor ACE2 and the cellular protease TMPRSS2 for entry into target cells. BioRxiv 2001.2031.929042

9. Hussain S, Pan J, Chen Y, Yang Y, Xu J, et al. (2005) Identification of novel subgenomic RNAs and noncanonical transcription initiation signals of severe acute respiratory syndrome coronavirus. J Virol 79: 5288-5295.
10. Letko M, Marzi A, Munster V (2020) Functional assessment of cell entry and receptor usage for SARS-CoV-2 and other lineage B betacoronaviruses. Nat Microbiol 5: 562569. [Crossref]

11. Perrier A, Bonnin A, Desmarets L, Danneels A, Goffard A, et al. (2019) The C-terminal domain of the MERS coronavirus M protein contains a trans- Golgi network localization signal. J Biol Chem 294: 14406-14421.

12. Xia S, Zhu Y, Liu M, Lan Q, Xu W, et al. (2020) Fusion mechanism of 2019- nCoV and fusion inhibitors targeting HR1 domain in spike protein. Cell Mol Immunol 17: 765-767. [Crossref]

13. Yu F, Du L, Ojcius DM, Pan C, Jiang S (2020) Measures for diagnosing and treating infections by a novel coronavirus responsible for a pneumonia outbreak originating in Wuhan, China. Microbes Infect 22: 74-79. [Crossref]

14. Riou J, Althaus CL (2020) Pattern of early human-to-human transmission of Wuhan 2019 novel coronavirus (2019-nCoV), December 2019 to January 2020. Euro Surveill 25: 2000058. [Crossref]

15. Yeo C, Kaushal S, Yeo D (2020) Enteric involvement of coronaviruses: is faecal-ora transmission of SARS-CoV-2 possible? Lancet Gastroenterol Hepatol 5: 335-337.

16. Yu P, Zhu J, Zhang Z, Han Y, Huang L (2020) A familial cluster of infection associated with the 2019 novel coronavirus indicating potential person-to-person transmission during the incubation period. J Infect Dis 221: 1757-1761.

17. Zhang W, Du R.H, Li B, Zheng XS, Yang XL, et al. (2020) Molecular and serologica investigation of 2019-nCoV infected patients: implication of multiple shedding routes. Emerg Microbes Infect 9: 386-389. [Crossref]

18. Zhou P, Yang XL, Wang XG, Hu B, Zhang L, et al. (2020) A pneumonia outbreak associated with a new coronavirus of probable bat origin. Nature 579: 270-273.

19. Qiu C, Deng Z, Xiao Q, Shu Y, Deng Y, et al. (2020) Transmission and clinical characteristics of coronavirus disease 2019 in 104 outside-wuhan patients, china. $J$ Med Virol 5: 10. [Crossref]

20. Duca A, Piva S, Foca E, Latronico N, Rizzi M (2020) Brescia-COVID Respiratory Severity Scale (BCRSS/Algorithm. Emergency Medicine Practice. Available at: www. ebmedicine.net

21. Ranieri VM, Rubenfeld GD, Thompson BT, Ferguson ND, Caldwell E, et al. (2012) ARDS definition task force. acute respiratory distress syndrome: The berlin definition. JAMA 307: 2526-2533.

22. Rodrigueza Y, Novelli L, Rojasa M, De Santis M, Acosta-Ampudia Y, et al. (2020) Autoinflammatory and autoimmune conditions at the crossroad of COVID-19. J Autoimm 1: 1-10.

23. van der Zee P, Rietdijk W, Somhorst P, Endeman H, Gommers D (2020) A systematic review of biomarkers multivariately associated with acute respiratory distress syndrome development and mortality. Cri Care 24: 243. [Crossref]

24. McCartney SA, Colonna M (2009) Viral sensors: diversity in pathogen recognition. Immun Rev 227:87-94.

25. Xinyi Lim Y, Ling Ng Y, Tam JP, Xiang Liu D (2016) Human coronaviruses: A review of virus-host interactions. Diseases 4: 26.

26. Lucchese G, Floel A (2020) SARS-CoV2 and Guillan-Barrè syndrome: molecular mimicry with human heat shock proteins as potential pathogenic mechanism. Cell Stress Chap 25: 731-735. [Crossref]

27. Lucchese G, Floel A (2020) Molecular mimicry between SARS-CoV-2 and respiratory pacemaker neurons. Autoimmun Rev 19: 102556.

28. Kanduc D, Shoenfeld Y (2020) On the molecular determinants of the SARS-CoV-2 attack. Clin Immunol 215: 108426.

29. Vabret N, Britton GJ, Gruber C, Hegde S, Kim J, et al. (2020) Immunology of COVID-19: Current state of the science immunity 52: 910-941.

30. Vojdani A, Kharrazian D (2020) Potential antigenic cross-reactivity between SARS$\mathrm{CoV}-2$ and human tissue with a possible link to an increase in autoimmune diseases. Clin Immunol 217: 108480. [Crossref]

31. Fiertz W, Walz B (2020) Antibody dependent enhancement due to original antigenic sin and development of SARS. Frontiers in Immunol 11: 1-5.

32. Ellul MA, Benjamin L, Singh B, Lant S, Michael BD, et al. (2020) Neurological associations of COVID-19.

33. Kamimura D, Tanaka Y, Hasebe R, Murakami M (2019) Bidirectional communication between neural and immune systems. Intern Immunol dxz083. [Crossref] 
34. Fotuhi M, Mian A, Meysami S, Raji CA (2020) Neurobiology of COVID-19. J Alzheimer Dis 76: 3-19. [Crossref]

35. Yaghi S, Torres J, Mac Grory B, Raz E, Humbert K, et al. (2020) SARS-CoV-2 and stroke in a New York Healthcare System. Stroke 51: 2002-2011.

36. Zhang JJ, Dong X, Cao YY, Yuan YD, Yang YB, et al. (2020) Clinical characteristics of 140 patients infected with SARS-CoV-2 in Wuhan, China. Allergy 75:1730-1741. [Crossref]

37. Chang J, He Q, Chen S, Hu Y (2020) Neurologic manifestations of hospitalized patients with coronavirus Disease 2019 in Wuhan. China. Jama Neurol 77: 683-690. [Crossref]

38. Zamorano JL, Ameri P, Giugliano RP (2020) Clinical consideration for anticoagulation in patients with COVID-19. Medscape 6/22.

39. Lazaridis C, Vlachogiannis NI, Bakogiannis C, Spyridopoulos I, Stamatelopoulos K, et al. (2020) Involvement of cardiovascular system as the critical point in coronavirus disease 2019 (COVID-19) prognosis and recovery. HJ Cardiol 1: 1-10.

40. Hirsch JS, Ng JH, Ross DW, Sharma P, Shah HH, et al. (2020) Acute kidney injury in patients hospitalized with COVID-19. Kidney Internat 98: 209-218.

41. Wang D, Hu B, Hu C, Zhu F, Liu X, et al. (2020) Clinical characteristics of 138 hospitalized patients with 2019 novel coronavirus-infected pneumonia in wuhan, china. JAMA 323: 1061-1069. [Crossref]

42. Zhang Y, Xiao M, Zhang S, Xia P, Cao W, et al. (2020) Coagulopathy and antiphospholipid antibodies in patients with Covid-19. New Engl J Med 382: e38.
43. Ma L, Wang W, Le Grange JM, Wang X, Du S, et al. (2020) Coinfection of SARSCoV-2 and other respiratory pathogens. Infect Drug Res 13: 3045-3052.

44. Dubey MJ, Ghosh R, Chatterjee S, Biswas P, Chatterjee S, et al. (2020) COVID-19 and addiction. Diabetes Metab Syndr 14: 817-823. [Crossref]

45. Jones BA, Grace D, Kock R, Alonso S, Rushton J, et al. (2013) Zoonosis emergence linked to agricultural intensification and environmental change. Proc Natl Acad Sci USA 21: 8399-8400.

46. Lai MM, Baric RS, Makino S, Keck JG, Egbert J, et al. (1985) Recombination between nonsegmented RNA genomes of murine coronaviruses. Jour Virol 56: 449-456.

47. Keck JG, Makino S, Soe LH, Fleming JO, Stohlman SA, et al. (1987) RNA recombination of coronavirus. Adv Exper Med Biol 218: 99-107. [Crossref]

48. Vijgen L, Keyaerts E, Moës E, Maes P, Duson G, et al. (2005) Development of onestep, real-time, quantitative reverse transcriptase pcr assays for absolute quantitation of human coronaviruses OC43 and 229E. J Clin Microbiol 43: 5452-5456.

49. Kruse RL (2020) Therapeutic strategies in an outbreak scenario to treat the novel coronavirus originating in Wuhan, China. F1000Res 9: 72. [Crossref]

50. Wang W, Xu Y, Gao R, Lu R, Han K, et al. (2020) Detection of SARS-CoV2 in differen types of clinical specimens. JAMA 323: 1843-1844.

51. van Doremalen N, Morris DH, Holbbrook MG, Gamble A, Williamson BN, et al. (2020) Aerosol and surface stability of SARS-CoV-2 as compared with SARS-CoV-1. New England J Med 382:

52. Kampf G, Todt D, Pfaender S, Steinmann E (2020) Persistence of coronaviruses on inanimate surfaces and their inactivation with biocidal agents. J Hosp Infect 104: 246-251.

Copyright: (2020 Patrizia F. This is an open-access article distributed under the terms of the Creative Commons Attribution License, which permits unrestricted use, distribution, and reproduction in any medium, provided the original author and source are credited. 